duty of making recommendations regarding the export trade. Cotton and rayon interests will be equally represented on the Committeo and the other principal bodies in the industry will be the Cotton Industry Advisory Committee, charged with examination of the sectional schemes, and the Representa. tive Advisory Council. Provision is also made for the establishment of a separate Rayon Industry Committee. Producers are compelled and merchants permitted to register with the Cotton Industry Board, but merchants will only be registered if they agree to abide by the contracts prescribed in sectional price schemes. Sectional schemes, which to become legally binding must be supported in a poll by the majority of the section concerned and approved by the Board, may relate to the elimination or reduction of redundant plant or to the fixing of prices. The broadsheet emphasizes the importance of marketing policy, the need for market research, the urgency of establish. ing central marketing arrangements, the necessity of a more enlightened labour policy than that which has short-sightedly sought exemptions from the Factories Act which reduced the juvenile working week from 48 to 44 hours, as well as the importance of implementing the permissive clause of the Act which allows the compensation of operatives displaced by redundancy schemes. Only long-term measures of this character can overcome the operatives' real and natural fear of technical change and eliminate the labour troubles which have contributed to the industry's difficulties.

\section{Mr. W. Gavin, C.B.E.}

IN further development of the organization which would be set up by the Government in the event of war to bring about an increase in food production in Great Britain, Mr. W. Gavin has been appointed agricultural adviser designate to the Minister of Agriculture and Fisheries. Mr. W. Gavin has already served in the Ministry of Agriculture, having been appointed in 1916 to act as assistant to the late Hon. E. G. Strutt, who was agricultural adviser throughout the war of 1914-18. Mr. Gavin afterwards became secretary and deputy director of the Army Cattle Committee, director of flax production and director of land reclamation. $\mathrm{He}$ is now the agricultural adviser to Imperial Chemical Industries, Ltd., a director of Strutt and Parker Farms, Xtd., a director of the Agricultural Mortgage Corporation, a member of council of the National Institute of Agricultural Botany, a trustee of the Lord Wands. worth Agricultural College, and an 'appointed' member of the executive of the Potato Marketing Eoard.

\section{Bernhard Naunyn (1839-1925)}

Bernhard NAUNYN, an eminent German physician and experimental pathologist, was born on September 2, 1939, in Berlin, where he studied medicine under Lieberkühn, Reichert and Frerichs. He qualified in 1862, and after acting as clinical assistant to Frerichs for some years, became successively professor of medicine at Dorpat (1869-71), Bern (1871),
Königsberg (1872-1888) and Strassburg (1888-1905). $\mathrm{He}$ was the author of two medical classics, the first on cholelithiasis (1892), which was translated into English by A. E. Garrod for the New Sydenham Society's publications (1896), and the second on diabetes mellitus (1898). Ho also wrote important articles on cerebral compression, the problem of fever, coagulation of the blood, gastric fermentation, cirrhosis of the liver, disorders of speech and syphilitic disease of the nervous system. Considerable historical interest is attached to his papers on "The Development of Internal Medicine in the Nineteenth Century", "The Berlin School 50 Years Ago" (1908), and his autobiography entitled "Erinnerungen, Gedanken und Meinungen". In 1872 ho founded, in conjunction with Schmiedeberg, the Archiv fïr experimentelle Pathologie und Pharmakologie, and in 1896, with the surgeon Mickulicz, the Mittheilungen aus den Grenzgebieten der Medizin und Chirurgie. Naunyn had many pupils who attained distinction, such as Eichhorst, Minkowski, Schreiber, Stadelmann, Umber and Weintraud. Ho remained active in his retirement at Baden-Baden until shortly before his death, which took place on July 26, 1925.

\section{Gift of Sutton Hoo Antiquities to the Nation}

Ar.x anxiety, which has been not inconsiderable, as to the future of the antiquities from the Sutton Hoo Anglo-Saxon royal ship-burial has been allayed by the announcement made by the Trustees of the British Museum (Bloomsbury) that Mrs. E. M. Pretty, declared their owner by the verdict of the Coroner's inquest of August 14 (see NATURE of August 19, p. 318), has generously presented them to the Museum. The gift is subject to $a$ condition that they shall be exhibited in due course on loan for a period in the Borough Museum of Ipswich. The gift comprises articles in gold, gems, and enamel, silver, bronze, iron, stone, wood, leather and textile fabrics-everything, in fact, which was found in the ship-burial on her estate at Sutton Hoo. Thus the relics from a find, which archæologically is the most important of its kind made in Great Britain, and the most valuable of its period made anywhere, not only become the property of the nation, but also will be preserved together as a whole. Had the collection been dispersed, as was feared possible, the discovery would have lost much of its unique value for cultural studies, and as tangible evidence for the whole complex of religious and social concepts, which inspired our Anglo-Saxon forbears in the seventh century of our era in their reactions to the demise of a chiefly head and representative of the community. Intrinsically valuable objects and jerrels in gold, silver, and enamel, especially when found in such rich profusion, impress the popular imagination : they afford evidence of a highly developed æsthetic faculty and superb skill in technique; but it is the humbler objects with which they are associated, the personal and domestic articles of the less precious metals, the pottery, the wood, leather, stone and the textiles, which are the more eloquent for the student of the culture of the time. They are the raw material 